\title{
Microstructure and mechanical properties of a 5754 aluminum alloy modified by $\mathrm{Sc}$ and $\mathrm{Zr}$ additions
}

\author{
Christian B. Fuller ${ }^{\mathrm{a}, *}$, Albert R. Krause ${ }^{\mathrm{b}}$, David C. Dunand ${ }^{\mathrm{a}}$, David N. Seidman ${ }^{\mathrm{a}}$ \\ a Department of Materials Science and Engineering, Northwestern University, 2225 North Campus Drive, Evanston, IL 60208-3108, USA \\ ${ }^{\mathrm{b}}$ Ford Motor Company, Scientific Research Laboratory, Dearborn, MI 48124, USA
}

Received 24 July 2001

\begin{abstract}
The effects of various heat treatments upon the microstructure and mechanical properties of a rolled 5754 aluminum alloy modified with $0.23 \mathrm{wt} . \% \mathrm{Sc}$ and $0.22 \mathrm{wt} . \% \mathrm{Zr}$ were investigated. Grain size, as well as precipitate size, type, and morphology were observed by optical and transmission electron microscopies. Two populations of the $\mathrm{Al}_{3} \mathrm{Sc}_{1-x} \mathrm{Zr}_{x}$ phase were present: (i) large incoherent precipitates formed during solidification and hot-rolling; and (ii) fine coherent precipitates formed from secondary precipitation, which improved alloy strength, as shown by hardness, tensile, and fatigue measurements. Aging, however, also produced two types of grain-boundary precipitates, $\mathrm{Al}_{6} \mathrm{Mn}$ and $\beta-\mathrm{Al}_{3} \mathrm{Mg}_{2}$, which contributed to poorer fatigue behavior and reduced ductility. (C) 2002 Elsevier Science B.V. All rights reserved.
\end{abstract}

Keywords: Al-Sc-Zr alloys; Fatigue (materials); Mechanical properties; Aluminum alloys; Microstructural properties

\section{Introduction}

New aluminum alloys that exhibit an optimal combination of strength, fatigue resistance, formability, and corrosion resistance are desirable for the ground-vehicle industry. One series of aluminum alloys currently in use is the $5 \mathrm{xxx}$ series, which was first developed for structural applications where corrosion resistance is important [1]. These alloys derive their strength from the solid-solution strengthening due to magnesium. Other alloying elements such as chromium, manganese, and zirconium are added for the control of grain and subgrain structures, which also contribute to strengthening. One approach toward improving the strength and recrystallization resistance of $5 \mathrm{xxx}$ aluminum alloys is to add small quantities of scandium [2]. Upon aging, fine coherent $\mathrm{Al}_{3} \mathrm{Sc}$ precipitates form with the ordered $\mathrm{Ll}_{2}$ structure, a lattice parameter misfit of $1.26 \%$ with $\mathrm{Al}$ [3], and a high stability up to the melting temperature of aluminum [4]. Due, however, to coarsening and solu-

\footnotetext{
* Corresponding author. Tel.: +1-847-491-3575; fax: +1-847-4672269.

E-mail address: c-fuller@northwestern.edu (C.B. Fuller).
}

tionizing, the grain-boundary pinning capability of $\mathrm{Al}_{3} \mathrm{Sc}$ precipitates decreases after long-term annealing, such as that required for the production of $5 \mathrm{xxx}$ series aluminum alloys [5]. This issue is addressed by improving the thermal stability of $\mathrm{Al}_{3} \mathrm{Sc}$ precipitates, for example, by adding zirconium to the alloy. This element substitutes for scandium (for up to half of the scandium atoms [6]) to form $\mathrm{Al}_{3} \mathrm{Sc}_{1-x} \mathrm{Zr}_{x}$ precipitates, which are more resistant to coarsening than binary $\mathrm{Al}_{3} \mathrm{Sc}$ precipitates [7]. Addition of $\mathrm{Zr}$ also decreases the price of the alloying additions.

While several researchers have shown that zirconium and scandium additions increase the recrystallization resistance and yield strength of 5xxx alloys [2,8,9], little information exists on the fatigue properties of these alloys. In a study by Wirtz et al. [10], an $\mathrm{Al}-4.0 \mathrm{Mg}-$ $0.3 \mathrm{Sc}$ (wt.\%) alloy was found to exhibit a higher resistance against fatigue crack nucleation than a 6013-T6 aluminum alloy. The increased fatigue resistance of the $\mathrm{Al}-\mathrm{Mg}-\mathrm{Sc}$ alloy was attributed to its very fine grain structure, compared to the coarser-grained 6013-T6 alloy. Since the combined additions of scandium and zirconium have been shown to improve the yield strength and recrystallization resistance of aluminum alloys, they may also improve the fatigue proper- 
ties. The present research tests this hypothesis by investigating the variation of microstructural and mechanical properties when scandium and zirconium additions are made to a 5754 aluminum alloy subjected to various thermo-mechanical treatments.

\section{Experimental procedures}

The alloy was fabricated by Canmet (Ottawa, Ont., Canada) in 6.3-mm thick sheets with the composition given in Table 1. The following thermo-mechanical treatments were reported by the supplier. The cast alloy was homogenized for one $\mathrm{h}$ at $400{ }^{\circ} \mathrm{C}$, hot rolled on an MTL single-stand reversing mill operating at a roller speed of $45 \mathrm{rpm}$ with a lubricant, using a series of reductions no greater than $24 \%$ per pass. Anneals at $400{ }^{\circ} \mathrm{C}$ were performed after every third pass to restore ductility, after which the alloy was air-cooled to ambient temperature. Rolling was performed until a final reduction of $1030 \%$ was achieved. Sample directions are given as $\mathrm{L}$ for the long direction (the rolling direction), ST for the short transverse direction (the thickness of the plate), and LT for the long transverse (the width of the plate). The as-rolled sheets were subjected to one of five heat treatments in this study: (1) aging at $288{ }^{\circ} \mathrm{C}$ for $72 \mathrm{~h}$; (2) aging at $300{ }^{\circ} \mathrm{C}$ for $72 \mathrm{~h}$; (3) annealing at $600{ }^{\circ} \mathrm{C}$ for $45 \mathrm{~min}$; or (4 and 5) a combination of the previous annealing treatment and one of the two above aging treatments. All heat treatments were terminated by quenching the samples into ice water.

Mechanical testing was performed at room temperature with the loading axis parallel to the rolling direction (L). Electro-discharge machining (EDM) was used to create tensile samples with a gauge length of $84.2 \mathrm{~mm}$, a width of $12.8 \mathrm{~mm}$, and a thickness of $6.3 \mathrm{~mm}$. Two samples for each heat-treatment were tested using an extensometer, in accordance with ASTM standard E-8. Flat-sheet fatigue specimens with a minimum rectangular cross-section of $6.3 \mathrm{~mm}$ by $6.3 \mathrm{~mm}$ were cut by EDM and were tested with an extensometer in accordance with ASTM standard E-606. Fatigue tests were performed with a closed loop, servo-hydraulic testing machine. Samples were tested with fully reversed $(R=$ $-1)$, constant strain cycles, which employed sinusoidal wave-forms at a frequency of $0.1-10 \mathrm{~Hz}$, depending on the strain amplitude.

Samples for optical microscopy and hardness measurements were sectioned from the sheets and cold

Table 1

Nominal chemical composition of modified 5754 alloy (in wt.\%)

\begin{tabular}{lllll}
\hline $\mathrm{Mg}$ & $\mathrm{Mn}$ & $\mathrm{Sc}$ & $\mathrm{Zr}$ & $\mathrm{Al}$ \\
\hline 3.42 & 0.63 & 0.23 & 0.22 & Balance \\
\hline
\end{tabular}

mounted, such that the L or ST direction was parallel to the observed plane. Polishing was performed with $\mathrm{SiC}$ paper and alumina slurries to obtain a surface finish of $0.03 \mu \mathrm{m}$. Polished samples were etched with Keller's solution (3 vol. $\%$ hydrofluoric acid and 2 vol. $\%$ nitric acid in water) or electrolytically etched with Barker's solution (5 vol.\% fluoroboric acid in water) and observed under cross-polarized light. These samples were also examined with a scanning electron microscope (SEM), operating at $12 \mathrm{kV}$, to identify large precipitates. Transmission electron microscopy (TEM) specimens were cut with their foil normals perpendicular to the rolling direction, mechanically thinned to 150 microns, and then jet-electropolished with an electrolyte of 5 vol. \% perchloric acid in methanol at a temperature of $30{ }^{\circ} \mathrm{C}$. Samples were observed utilizing a JEOL 2000 FX or a Hitachi H-8100 TEM operating at $200 \mathrm{kV}$. In all cases, the presence of $\mathrm{Al}_{3} \mathrm{Sc}_{1-x} \mathrm{Zr}_{x}$ precipitates was determined by dark-field imaging utilizing the (100) and (110) $\mathrm{L1}_{2}$ superlattice diffraction spots of the precipitates. Identification of other phases $\left(\mathrm{Al}_{6} \mathrm{Mn}\right.$ and $\beta$ $\mathrm{Al}_{3} \mathrm{Mg}_{2}$ ) was performed by employing a combination of energy dispersive X-ray spectroscopy (EDS) and selected area electron diffraction patterns.

\section{Results and discussion}

\subsection{Microstructure}

\subsubsection{Optical microscopy}

The as-rolled material exhibits a dense pancakeshaped grain structure, which is typical of as-rolled material (Fig. 1). Observation along the L-direction does not yield distinct demarcations among grains. Isolated primary $\mathrm{Al}_{3} \mathrm{Sc}_{1-x} \mathrm{Zr}_{x}$ precipitates, which formed upon

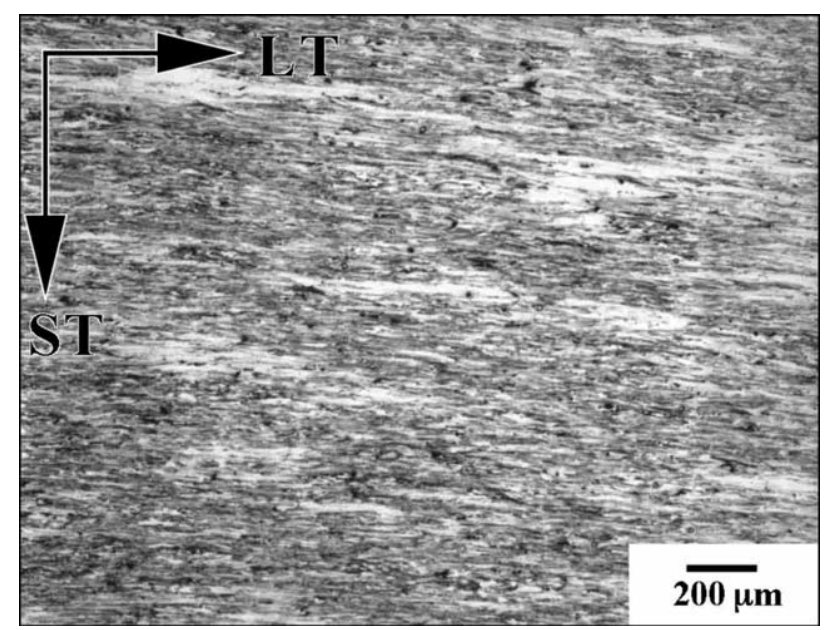

Fig. 1. Optical micrograph of the modified 5754 alloy in the as-rolled state showing the grain structure in the ST direction (Keller's etch). 
solidification, are observed to have a cuboidal shape and an edge length varying from 2 to $10 \mu \mathrm{m}$.

Aging the alloy at $288{ }^{\circ} \mathrm{C}$ for $72 \mathrm{~h}$ produces little change in the grain structure, precipitate size, and distribution from the as-rolled condition. The sample aged at $300{ }^{\circ} \mathrm{C}$ for $72 \mathrm{~h}$ exhibits, however, the first signs of recrystallization, as evidenced by regions consisting of several crystallographic orientations, as shown by the mixing of interference colors within each etched region (Fig. 2a, shown in grayscale). Etching of the sample aged at $300{ }^{\circ} \mathrm{C}$ with Keller's solution reveals a network of precipitates along the region's boundary (Fig. 2b, arrow 1). Also shown in Fig. $2 b$ is a primary $\mathrm{Al}_{3} \mathrm{Sc}_{1-x} \mathrm{Zr}_{x}$ precipitate (arrow 2), which is most likely formed during solidification of the ingot and a $\beta-\mathrm{Al}_{3} \mathrm{Mg}_{2}$ precipitate (arrow 3 ).

The annealing treatment $\left(600{ }^{\circ} \mathrm{C}\right.$ for $\left.45 \mathrm{~min}\right)$ causes recrystallization, which may be followed by some grain growth (Fig. 3), with a grain areal density of $1221 \pm 413$ grains $\mathrm{mm}^{-2}$. Etching of this sample with Keller's solution does not reveal a network of precipitates along the grain boundaries. Further aging the $600{ }^{\circ} \mathrm{C}$ annealed alloys at $288{ }^{\circ} \mathrm{C}$ or $300{ }^{\circ} \mathrm{C}$ for $72 \mathrm{~h}$, (Fig. $4 \mathrm{a}$ and $\mathrm{b}$, respectively) may result in further grain growth (grain

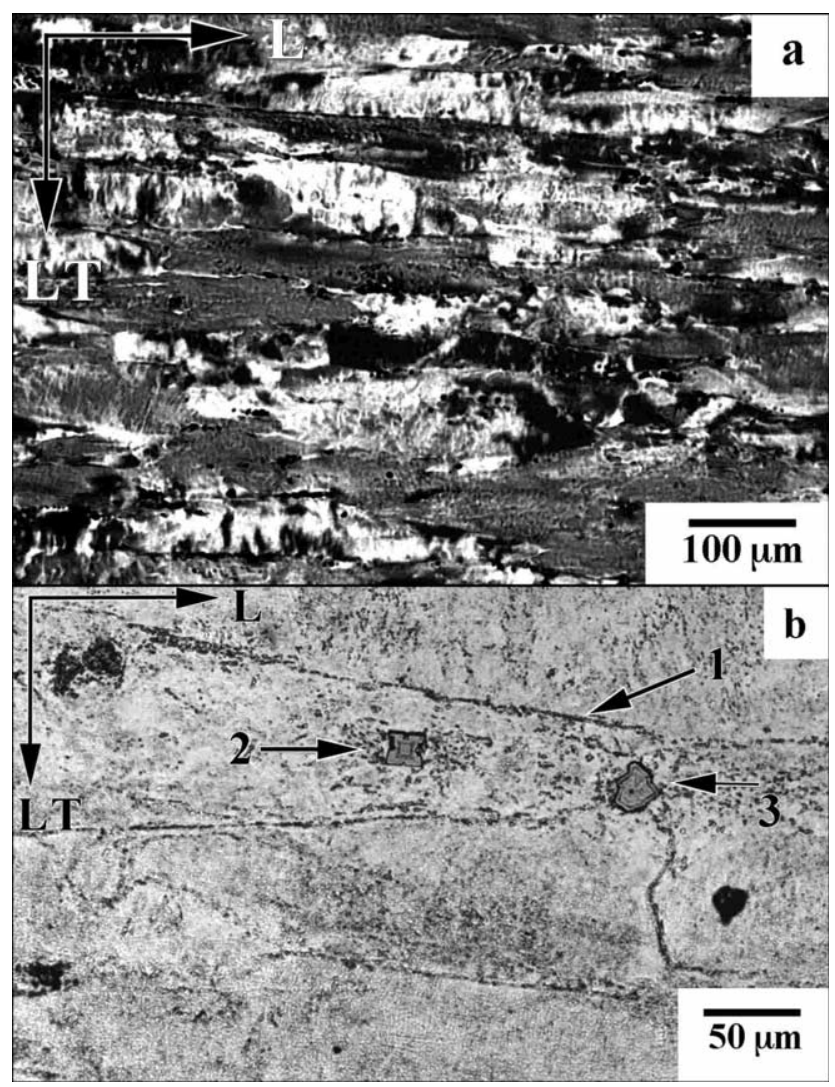

Fig. 2. Optical micrograph of the modified 5754 alloy aged at $300{ }^{\circ} \mathrm{C}$ for $72 \mathrm{~h}$ illustrating: (a) large grains (Barker's etch); and (b) grain boundary precipitates (arrow 1) (Keller's etch). Also shown in (b) are a primary $\mathrm{Al}_{3} \mathrm{Sc}_{1-x} \mathrm{Zr}_{x}$ precipitate (arrow 2 ) and a $\beta-\mathrm{Al}_{3} \mathrm{Mg}_{2}$ precipitate (arrow 3).

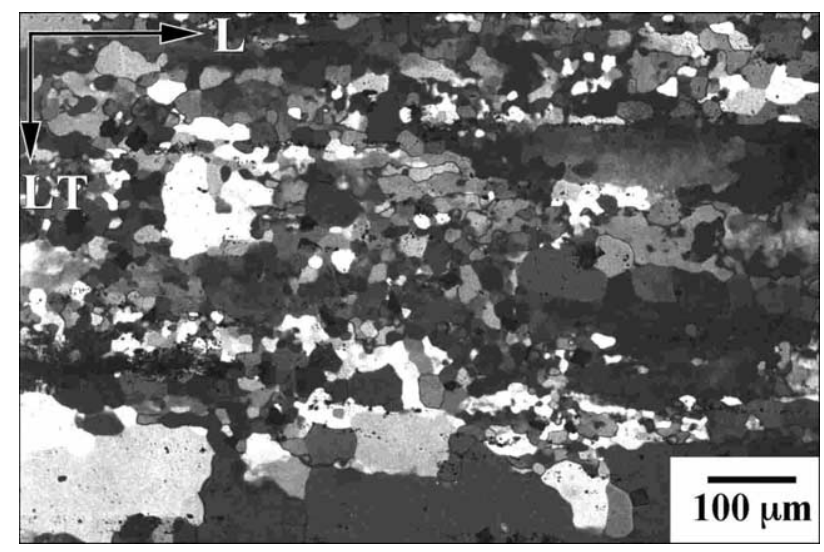

Fig. 3. Optical micrograph of the modified 5754 alloy annealed at $600{ }^{\circ} \mathrm{C}$ for 45 min exhibiting a recrystallized grain structure (Barker's etch).

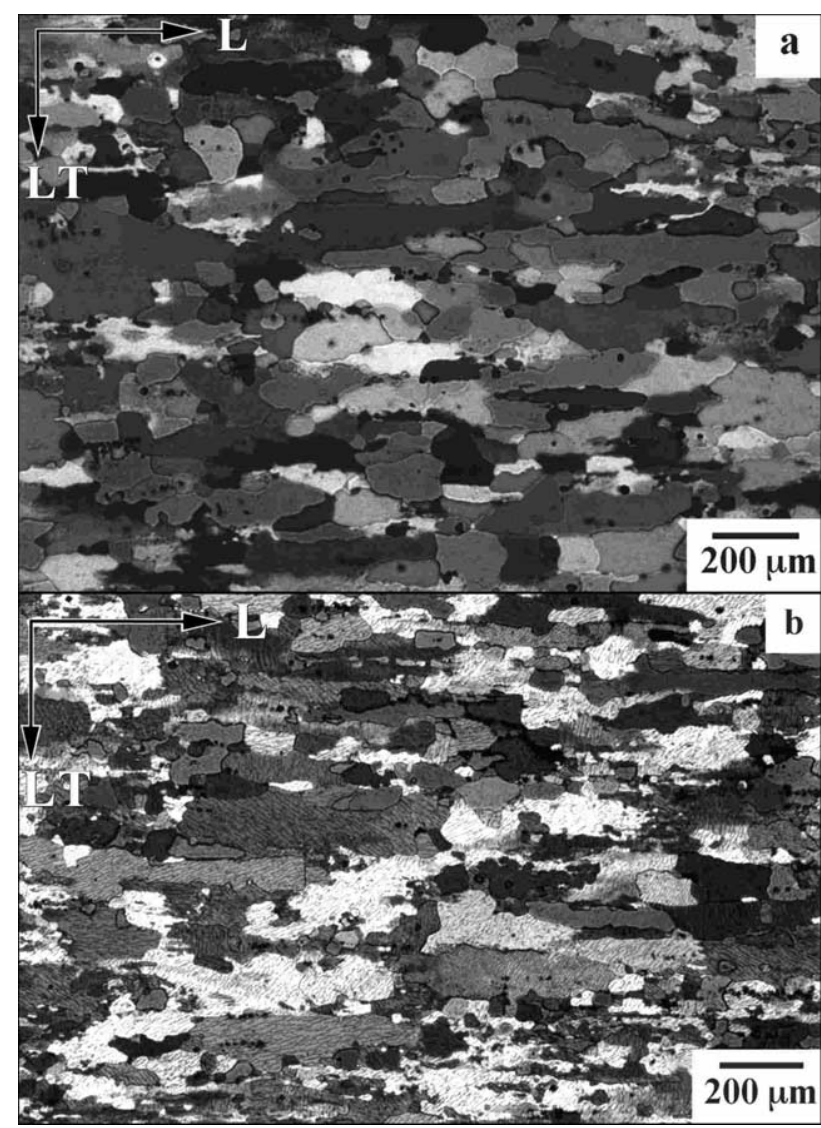

Fig. 4. Optical micrograph of elongated grains produced by annealing the modified 5754 alloy at $600{ }^{\circ} \mathrm{C}$ for $45 \mathrm{~min}$ and aging at: (a) $288{ }^{\circ} \mathrm{C}$ for $72 \mathrm{~h}$; or (b) $300{ }^{\circ} \mathrm{C}$ for $72 \mathrm{~h}$ (both Barker's etch).

areal density of $178 \pm 27$ grains $\mathrm{mm}^{-2}$ ) and produces more elongated grains in comparison to those of the annealing heat-treatment, (Fig. 3). Both aging treatments lead to the presence of precipitate networks along the grain boundaries, as discussed below. 


\subsubsection{Transmission electron microscopy (TEM)}

Four specimens were observed by TEM with the following heat treatments: (1) as-rolled; (2) aged at $288{ }^{\circ} \mathrm{C}$ for $72 \mathrm{~h}$.; (3) annealed at $600{ }^{\circ} \mathrm{C}$ for $45 \mathrm{~min}$; or (4) annealed at $600{ }^{\circ} \mathrm{C}$ for $45 \mathrm{~min}$ followed by aging at $288{ }^{\circ} \mathrm{C}$ for $72 \mathrm{~h}$. All four samples contained secondphase precipitates with $\mathrm{Al}_{6} \mathrm{Mn}$ and $\mathrm{Al}_{3} \mathrm{Sc}_{1-x} \mathrm{Zr}_{x}$ compositions. The $\mathrm{Al}_{6} \mathrm{Mn}$ precipitates showed no change in size $(1 \mu \mathrm{m} \times 0.7 \mu \mathrm{m})$ for all four heat treatments. There was, however, a difference in the size and morphology of the $\mathrm{Al}_{3} \mathrm{Sc}_{1-x} \mathrm{Zr}_{x}$ precipitates for each specimen, as listed in Fig. 5.

The as-rolled sample exhibited $\mathrm{Al}_{3} \mathrm{Sc}_{1-x} \mathrm{Zr}_{x}$ precipitates in the form of incoherent rods (Fig. 6, arrow A) with a length of $172 \pm 16 \mathrm{~nm}$, a diameter of $31 \pm 2 \mathrm{~nm}$, and a corresponding length-to-diameter aspect ratio of about 6 . These rods were found to be oriented parallel to the L-direction of the alloy. Also observed were smaller coherent, $\mathrm{Al}_{3} \mathrm{Sc}_{1-x} \mathrm{Zr}_{x}$ precipitates (Fig. 6, arrow B, $25 \pm 3 \mathrm{~nm}$ diameter), and a dense network of subgrains (Fig. 7), which formed during the hot-rolling process. The presence of subgrain boundaries was confirmed by employing TEM analyses of crystal disorientations as indicated by electron diffraction patterns; an example of a subgrain boundary is given in Fig. 7 where a small variation in disorientation, while remaining near the [113] zone axis, was detected while moving across this boundary from point A to B.

Aging of the as-rolled material (at $288{ }^{\circ} \mathrm{C}$ for $72 \mathrm{~h}$ ) resulted in three morphologies for the $\mathrm{Al}_{3} \mathrm{Sc}_{1-x} \mathrm{Zr}_{x}$ precipitates (Fig. 8). Both $\mathrm{Al}_{3} \mathrm{Sc}_{1-x} \mathrm{Zr}_{x}$ morphologies present in the as-rolled alloy were found (Fig. 5); rodshaped precipitates (Fig. 8b), with an increased length and a diameter similar to the rods in the rolled alloy and incoherent spheroidal $\mathrm{Al}_{3} \mathrm{Sc}_{1-x} \mathrm{Zr}_{x}$ precipitates, with an increased diameter over the precipitates in the rolled alloy (and a attendant loss of coherency). Third, a new population of fine coherent $\mathrm{Al}_{3} \mathrm{Sc}_{1-x} \mathrm{Zr}_{x}$ precipitates

\begin{tabular}{|c|c|c|c|c|c|}
\hline \multicolumn{2}{|c|}{$\begin{array}{c}\mathrm{Al}_{3} \mathrm{SC}_{1-x \mathrm{r}} \mathrm{Zr}_{\mathrm{x}} \\
\text { precipitates } \\
(\mathrm{nm})\end{array}$} & As-Rolled & $\begin{array}{c}288^{\circ} \mathrm{C} \\
\text { for } 72 \mathrm{~h} .\end{array}$ & $\begin{array}{c}600^{\circ} \mathrm{C} \\
\text { for } 45 \mathrm{~min} .\end{array}$ & $\begin{array}{c}600^{\circ} \mathrm{C} \text { for } 45 \mathrm{~min} . \\
+288^{\circ} \mathrm{C} \text { for } 72 \mathrm{~h} .\end{array}$ \\
\hline $\begin{array}{c}\text { length } \mathrm{x} \\
\text { thickness }\end{array}$ & Rods & $\begin{array}{c}172 \pm 16 \\
\times 31 \pm 2\end{array}$ & $\begin{array}{c}202 \pm 32 \\
\times 33 \pm 4\end{array}$ & N. Obs. & N. Obs. \\
\hline \multirow{2}{*}{ diameter } & $\begin{array}{c}\text { Large } \\
\text { spheroids }\end{array}$ & $25 \pm 3^{+}$ & $39 \pm 4$ & $42 \pm 3$ & $54 \pm 5$ \\
\cline { 2 - 6 } & $\begin{array}{c}\text { Small } \\
\text { spheroids }\end{array}$ & N.Obs. & $8.7 \pm 0.8^{+}$ & N. Obs. & $12.3 \pm 0.6^{+}$ \\
\hline
\end{tabular}

Fig. 5. $\mathrm{Al}_{3} \mathrm{Sc}_{1-x} \mathrm{Zr}_{x}$ precipitate evolution in modified 5754 alloys as a function of heat-treatment to the as-rolled alloy. Arrows illustrate how precipitates change during the indicated heat-treatment, (see text for full explanation). The error ranges denote the errors in measurements of the precipitates (error associated with NIH image, $4 \%$ in this study) plus one standard deviation of the precipitate distribution divided by the square root of the number of precipitates in the distribution. The superscript plus sign $\left({ }^{+}\right)$indicates that the precipitates are coherent and N.Obs. denotes that precipitates are not observed.

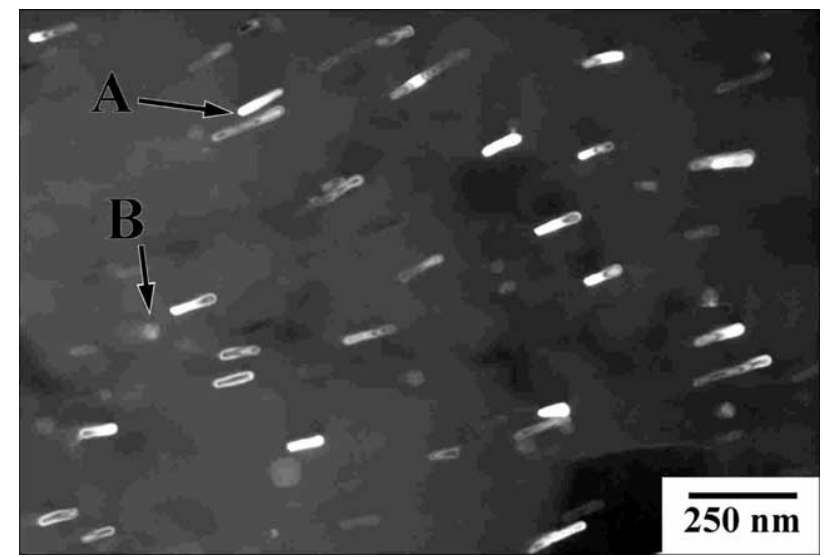

Fig. 6. Centered superlattice dark-field TEM micrograph, [111] zone axis, of the modified 5754 alloy in the as-rolled state, illustrating the presence of $\mathrm{Al}_{3} \mathrm{Sc}_{1-x} \mathrm{Zr}_{x}$ precipitates as rod-shaped precipitates (arrow A) and finer spheroidal precipitates (arrow B).

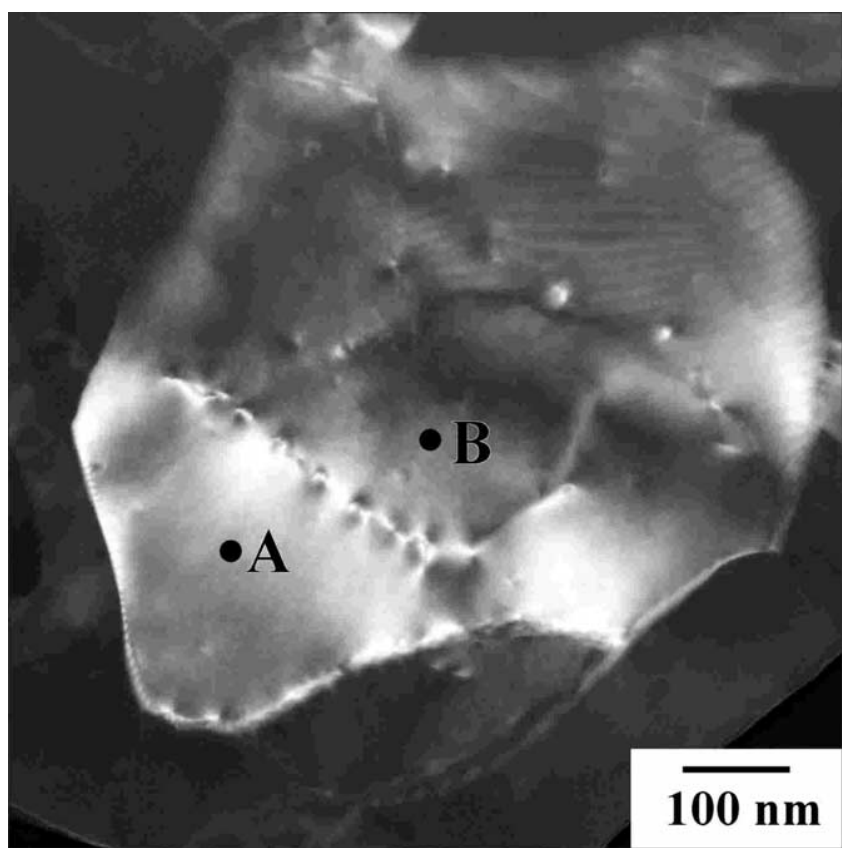

Fig. 7. Centered bright-field TEM micrograph, [113] zone axis, of the modified 5754 alloy in the as-rolled state, illustrating the presence of subgrain boundaries. Points A and B mark the locations of the crystal disorientation analyses, performed to confirm the presence of subgrain boundaries.

$(8.7 \pm 0.8 \mathrm{~nm}$ diameter $)$ was present. The fine precipitates were found to be located primarily within small grains, as seen in Fig. 8a. It is likely that the incoherent $\mathrm{Al}_{3} \mathrm{Sc}_{1-x} \mathrm{Zr}_{x}$ rods and large spheroids depleted the scandium and zirconium concentrations in their vicinity leaving a non-uniform distribution of the fine coherent $\mathrm{Al}_{3} \mathrm{Sc}_{1-x} \mathrm{Zr}_{x}$ precipitates.

The main purpose of the $600{ }^{\circ} \mathrm{C}$ annealing treatment was to utilize recrystallization to increase the as-rolled grain size and enable easier mechanical processing, 


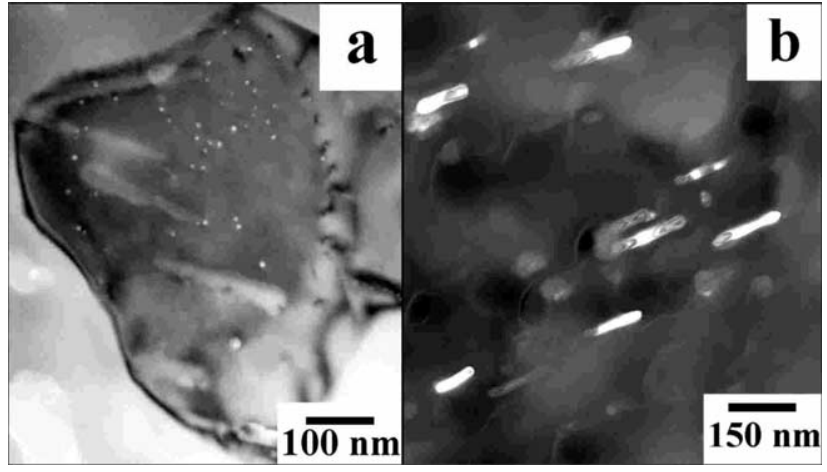

Fig. 8. Centered superlattice dark-field TEM micrograph, [111] zone axis, of $\mathrm{Al}_{3} \mathrm{Sc}_{1-x} \mathrm{Zr}_{x}$ precipitates after aging at $288{ }^{\circ} \mathrm{C}$ for $72 \mathrm{~h}$ illustrating: (a) fine coherent $\mathrm{Al}_{3} \mathrm{Sc}_{1-x} \mathrm{Zr}_{x}$ precipitates and (b) incoherent $\operatorname{rod} \mathrm{Al}_{3} \mathrm{Sc}_{1-x} \mathrm{Zr}_{x}$ precipitates.

which was achieved as Fig. 3 demonstrates. A TEM examination of the recrystallized structure indicated that both subgrain and dislocation networks have been eliminated during the annealing heat-treatment, so that the strengthening of the annealed and aged sample can be primarily attributed to the small grain size and the presence of precipitates. Annealing produced incoherent spheroidal $\mathrm{Al}_{3} \mathrm{Sc}_{1-x} \mathrm{Zr}_{x}$ precipitates with a $42 \pm 3 \mathrm{~nm}$ diameter, some of which can be observed pinning grain boundaries (Fig. 9). Subsequent aging at $288{ }^{\circ} \mathrm{C}$ produced two populations of $\mathrm{Al}_{3} \mathrm{Sc}_{1-x} \mathrm{Zr}_{x}$ precipitates (Fig. 10), one with large diameters $(54 \pm 5 \mathrm{~nm})$, probably formed initially during the $600{ }^{\circ} \mathrm{C}$ anneal and somewhat grown in size during aging, and one with a smaller size $(12.3 \pm 0.6 \mathrm{~nm}$ diameter), which probably precipi-

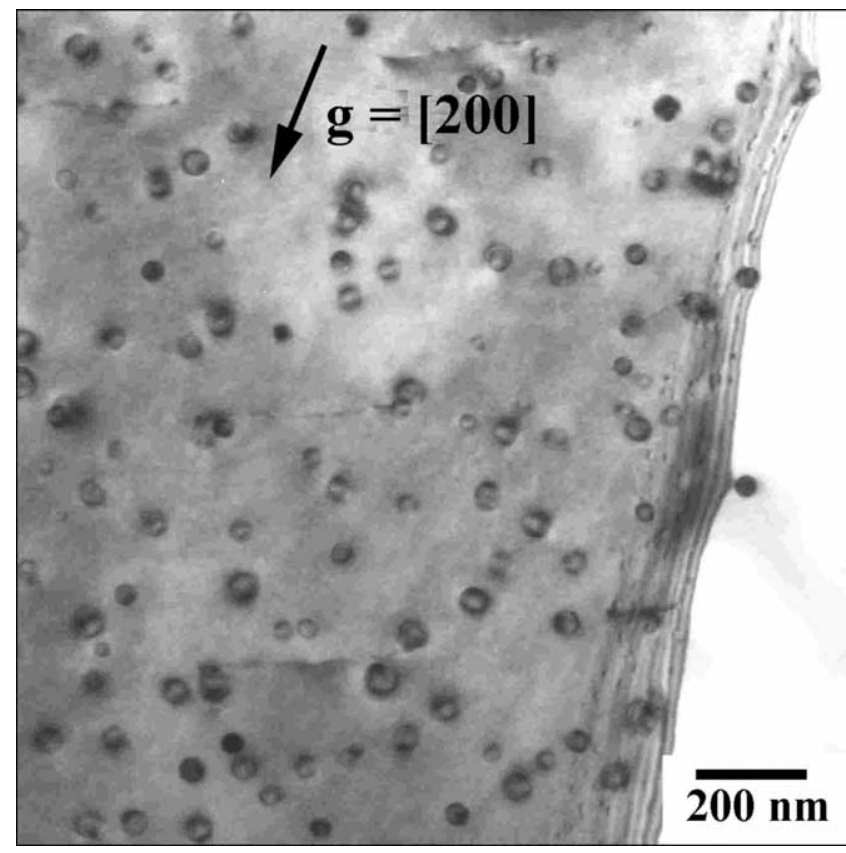

Fig. 9. Two-beam, $\mathbf{g}=[200]$, bright-field TEM micrograph of incoherent spheroidal $\mathrm{Al}_{3} \mathrm{Sc}_{1-x} \mathrm{Zr}_{x}$ precipitates after annealing at $600{ }^{\circ} \mathrm{C}$ for $72 \mathrm{~h}$.

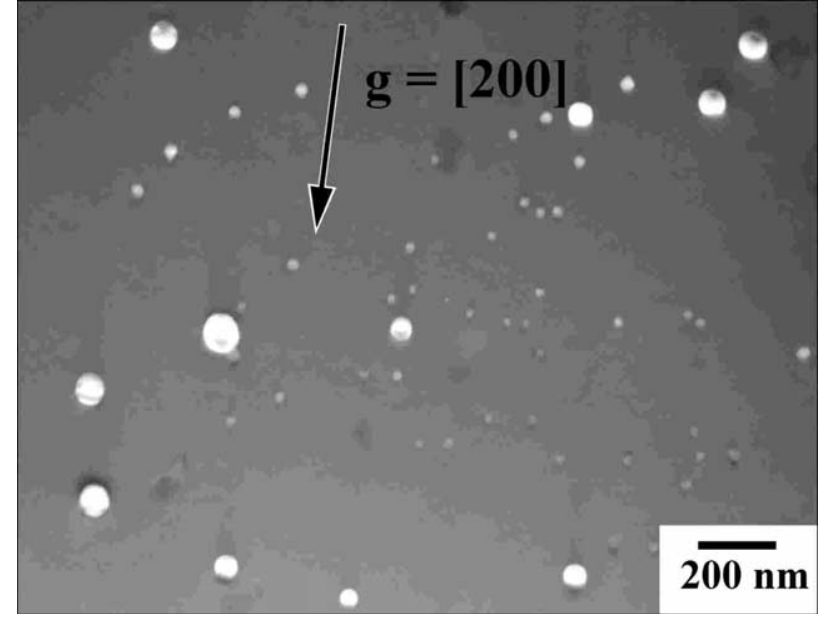

Fig. 10. Two-beam, $\mathbf{g}=$ [200], superlattice dark-field TEM micrograph of $\mathrm{Al}_{3} \mathrm{Sc}_{1-x} \mathrm{Zr}_{x}$ precipitates present after annealing $\left(600{ }^{\circ} \mathrm{C}\right.$ for 45 min) and aging $\left(288{ }^{\circ} \mathrm{C}\right.$ for $\left.72 \mathrm{~h}\right)$. Both incoherent spheroidal precipitates and fine coherent precipitates are observed.

tated during the $288{ }^{\circ} \mathrm{C}$ treatment. The smaller precipitates are coherent, as indicated by the strain-field contrast (so-called Ashby-Brown or coffee-bean contrast) associated with each precipitate.

The evolution of the $\mathrm{Al}_{3} \mathrm{Sc}_{1-x} \mathrm{Zr}_{x}$ precipitate morphology is given in Fig. 5 and a possible explanation for this evolution is outlined here. The large rod-like precipitates $(172 \pm 16 \mathrm{~nm} \times 31 \pm 2 \mathrm{~nm})$ in the as-rolled alloy are most likely the result of a discontinuous precipitation mechanism (also known as cellular precipitation), which has been observed previously in the $\mathrm{Al}-\mathrm{Sc}$ [3] and $\mathrm{Al}-\mathrm{Zr}$ systems [11]. Cellular precipitation occurs when a supersaturated solid-solution decomposes into matrix and precipitate phases behind an advancing grain boundary [12]. The numerous short-term, intermediate $400{ }^{\circ} \mathrm{C}$ aging treatments performed between rolling passes also produced the second population of smaller spheroidal precipitates $(25 \pm 3 \mathrm{~nm}$ diameter $)$. Long-term aging of this as-rolled structure at $288{ }^{\circ} \mathrm{C}$ led to modest growth of these large incoherent rods and spheroids, while the fine coherent spheroids formed in solute-rich regions without prior incoherent precipitates. Annealing of the as-rolled alloy at $600{ }^{\circ} \mathrm{C}$ resulted in the disappearance of the fine coherent precipitates by dissolution, as the solid-solubility of $\mathrm{Sc}$ and $\mathrm{Zr}$ increases with increasing temperature. The spheroidal precipitates are most probably the result of splitting and spheroidizing of the rods with a high surface-to-volume ratio, thus recovering a precipitate shape with higher stability than the rods. A complete dissolution followed by precipitation is less likely, because a temperature of $600{ }^{\circ} \mathrm{C}$ is not high enough to dissolve completely the large $\mathrm{Al}_{3} \mathrm{Sc}_{1-x} \mathrm{Zr}_{x}$ precipitates [13]. The ratio of the volumes of the rods (in the as-rolled plus aged alloy) to spheroids (in the annealed alloy) gives a value of 4.5; that is each rod produces four to five spheroids. Long lines of 
spherical precipitates are thus not expected and are indeed not observed. Subsequent aging at $288{ }^{\circ} \mathrm{C}$ for $72 \mathrm{~h}$ after annealing at $600{ }^{\circ} \mathrm{C}$ for 45 min resulted in growth of the incoherent spheroidal precipitates (from $42 \pm 3$ to $54 \pm 5 \mathrm{~nm}$ diameter) formed during annealing, and precipitation of coherent precipitates $(12.3 \pm 0.6 \mathrm{~nm}$ diameter), similar in size to those observed upon aging of the as-rolled alloy $(8.7 \pm 0.8 \mathrm{~nm}$ diameter $)$.

The goal of the aging treatments was to precipitate scandium and zirconium present in solid solution after rolling or annealing to increase the strength of the alloy. As is apparent, however, from the optical micrographs (Fig. 2b), the aging treatments also resulted in precipitate networks at grain boundaries. TEM examination of the grain boundaries revealed two types of grain boundary precipitates: (i) large cuboidal $\mathrm{Al}_{6} \mathrm{Mn}$ precipitates ( $1 \mu \mathrm{m}$ diameter); and (ii) small, Mn containing precipitates (100 nm diameter). The large precipitates, which are present in all of the alloys we studied, are expected to form in 5754 alloys and are used for control of subgrain and grain structures during alloy processing [1]. The small Mn-containing precipitates result from the aging treatments and are not observed in the as-rolled and annealed alloys. SEM observations revealed decorated grain boundaries as shown in Fig. 2b, which consist of the $\mathrm{Al}_{6} \mathrm{Mn}$ phase mentioned above and a larger $\left(3-26 \mu \mathrm{m}\right.$ in diameter) $\beta-\mathrm{Al}_{3} \mathrm{Mg}_{2}$ phase. The formation of a precipitate network along grain boundaries is expected to have a negative effect on the mechanical properties of the alloy, as discussed below.

\subsection{Mechanical properties}

\subsubsection{Hardness}

Vickers microhardness measurements were used as an initial assessment of the effect of the different heat treatments upon mechanical properties (Fig. 11). The highest hardness was measured in the as-rolled material. The lowest hardness was observed after the $45 \mathrm{~min}$. anneal at $600{ }^{\circ} \mathrm{C}$, as expected since this treatment is effective in dissolving the fine precipitates (Fig. 5), recrystallizing the grain structure (Fig. 3), decreasing the dislocation density, and eliminating subgrains. The increase in hardness of the alloys aged at 300 or $288{ }^{\circ} \mathrm{C}$, after the $600{ }^{\circ} \mathrm{C}$ annealing treatment, indicates that the fine $\mathrm{Al}_{3} \mathrm{Sc}_{1-x} \mathrm{Zr}_{x}$ precipitates make a large contribution to the strength of the alloy. It is also noted that a $12{ }^{\circ} \mathrm{C}$ difference ( 300 vs. $288{ }^{\circ} \mathrm{C}$ ) has a significant effect on the number density of precipitates formed, as observed by the differences in hardness and with TEM, and as previously reported by Hyland [4] and Marquis and Seidman [14] in other $\mathrm{Al}(\mathrm{Sc})$ alloys.

\subsubsection{Tensile properties}

The microstructures discussed above demonstrate that there are three contributions to strengthening. First

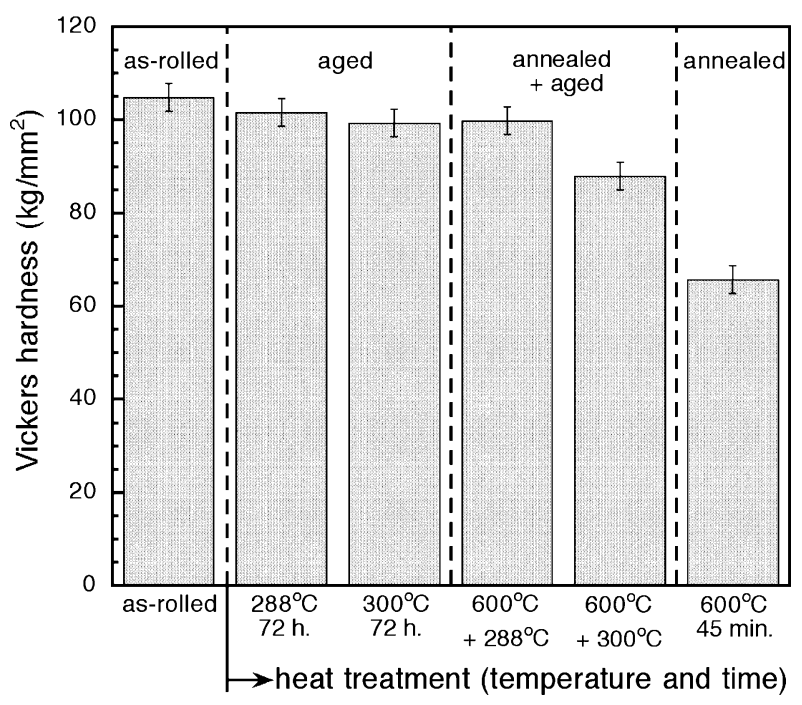

Fig. 11. Hardness of modified 5754 alloy with indicated heat treatments.

are the $\mathrm{Al}_{3} \mathrm{Sc}_{1-x} \mathrm{Zr}_{x}$ precipitates that exist in two different populations: large incoherent rods or spheroids, which provide Orowan strengthening, and small coherent spheroidal precipitates, which strengthen the alloy by the shearing or Orowan looping mechanisms. The second contribution to strengthening is from both subgrain and grain boundaries, and the third contribution is from dislocation networks (forest dislocation hardening).

The tensile properties of the unmodified 5754 alloy in the O-tempered state $\left(343{ }^{\circ} \mathrm{C}\right.$ for $\left.1 \mathrm{~h}\right)$ and of the modified 5754 specimens with four different heat treatments described above (as-rolled, aged at $288{ }^{\circ} \mathrm{C}$ for 72 $\mathrm{h}$, annealed at $600{ }^{\circ} \mathrm{C}$ for $45 \mathrm{~min}$, or a combination of the latter two treatments) are displayed in Fig. 12. A comparison of the tensile properties with the hardness results indicates similar trends that can be correlated

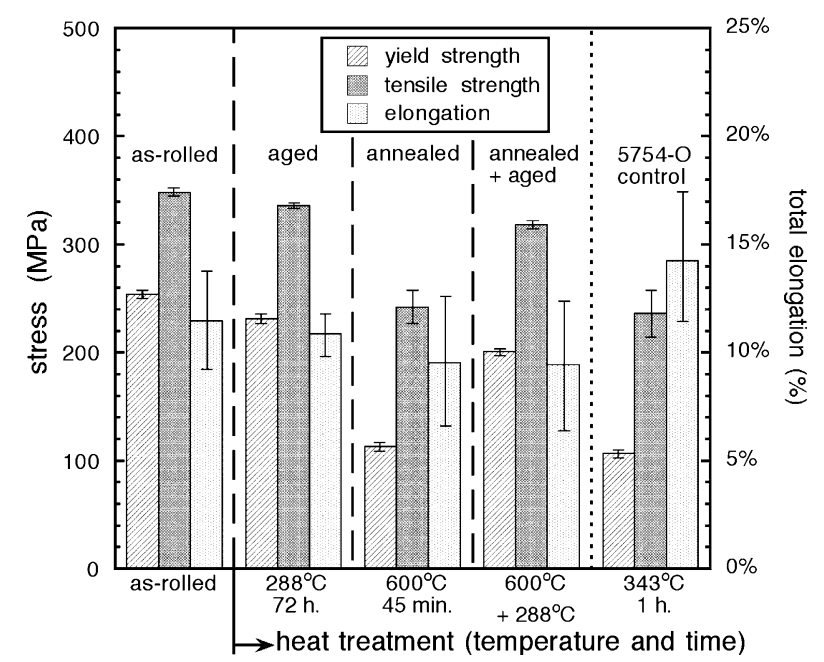

Fig. 12. Tensile properties of modified 5754 and baseline 5754-O alloys with indicated heat treatments. 
with the strengthening contributions as noted above. The high strength of the as-rolled alloy stems from contributions from precipitates, a high density of grain and subgrain boundaries (due to extensive hot working and pinning by precipitates), and the presence of dislocation networks formed during hot-working. Aging of the as-rolled alloy $\left(288{ }^{\circ} \mathrm{C}\right.$ for $\left.72 \mathrm{~h}\right)$ leads to precipitation of the coherent fine $\mathrm{Al}_{3} \mathrm{Sc}_{1-x} \mathrm{Zr}_{x}$ precipitates, which increases the contribution of coherent precipitate strengthening. Also, recrystallization has begun (Fig. 2), which decreases the contribution of grain structures to strengthening. Furthermore, the aging time was sufficiently long to reduce the dislocation density present in the material. Therefore, the diminution in tensile properties from the as-rolled to the aged state originates from a net decrease in all three contributions to strengthening.

Annealing of the as-rolled alloy results in the dissolution of the fine $\mathrm{Al}_{3} \mathrm{Sc}_{1-x} \mathrm{Zr}_{x}$ precipitates (eliminating completely the coherent precipitate contribution) and a transformation of the rods into spheroids with smaller interprecipitate spacings, resulting in a modest increase of strengthening. Grains have recrystallized (Fig. 3), while the subgrain and dislocation densities have been effectively eliminated, both of which contribute to a decrease in strengthening. The net effect is a further decrease in strength, since the annealed alloy is the weakest of all the alloys studied. Subsequent aging of the annealed alloy at $288{ }^{\circ} \mathrm{C}$ for $72 \mathrm{~h}$ leads to the formation of fine coherent $\mathrm{Al}_{3} \mathrm{Sc}_{1-x} \mathrm{Zr}_{x}$ precipitates and perhaps grain growth. Thus, as seen in the improvement in tensile properties upon aging, the fine precipitate contribution to the strength of this alloy overcomes the strength decrease due to recrystallization and perhaps grain growth.

An unexpected result was the reduction of ductility upon heat-treatment (Fig. 12), since ductility generally increases when strength decreases. This is evidence that embrittlement is occurring, which is a result of grain boundary precipitation.

\subsubsection{Fatigue properties}

The fatigue behavior of modified 5754 specimens with three different heat treatments (as-rolled, $600{ }^{\circ} \mathrm{C}$ for 45 min, or $600{ }^{\circ} \mathrm{C}$ for $45 \mathrm{~min}$ plus $288{ }^{\circ} \mathrm{C}$ for $72 \mathrm{~h}$ ) are compared with that of the 5754-O alloy in Fig. 13. Fatigue resistance was the greatest for the as-rolled specimens and the lowest for the annealed specimens, with the annealed and aged specimens in an intermediate position. As expected, the same ranking is observed in terms of static strength, which was justified previously in terms of strengthening mechanisms. The fatigue life of the as-rolled alloy is two to ten times longer than that of the control 5754-O alloy, the improvement increasing with decreasing strain amplitude.

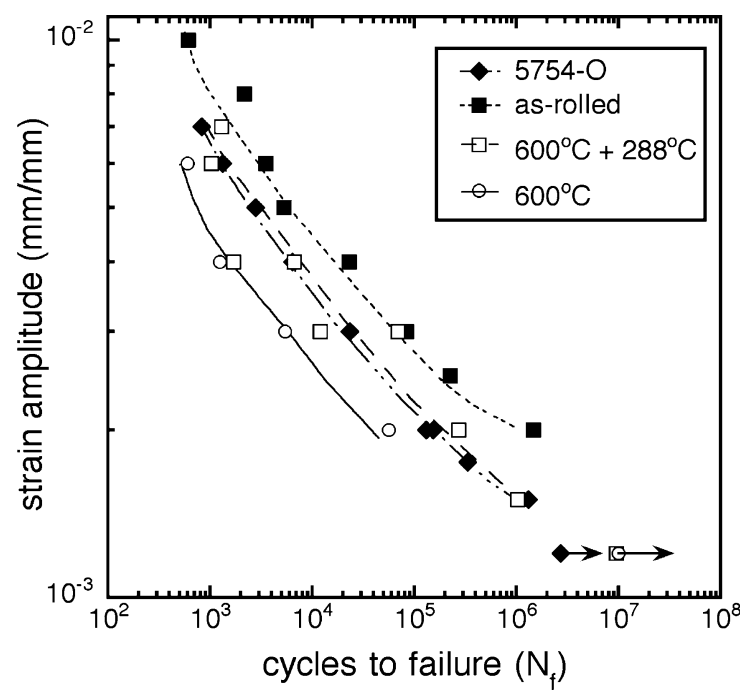

Fig. 13. A double logarithmic plot of strain amplitude versus number of cycles to failure for modified 5754 and unmodified 5754-O alloys with indicated heat treatments; arrows indicate samples that did not fracture.

As shown in Fig. 11, all the heat treatments of the modified 5754 alloy have a higher static strength than the 5754-O alloy. However, the fatigue results in Fig. 13 indicate that not all heat treatments to the modified 5754 alloy are beneficial to fatigue resistance: the annealed modified alloy has a fatigue life two to five times lower than the control alloy. Strain controlled fatigue is more sensitive to microstructural flaws (due to the localized effect of stress on the microstructure) than stress-controlled fatigue and static strength, which are affected by nominal stresses and strains [15]. Thus, strain-controlled fatigue allows the separation of microstructural components that are effective in inhibiting fatigue and those that contribute to flaws. In the case of the modified 5754 alloys, strain-controlled fatigue can reveal local microstructural flaws that form as a result of heat-treatment of the as-rolled alloy. The presence of these flaws is confirmed by the relatively high amount of scatter in the fatigue data presented in Fig. 13, especially for the annealed and aged specimens. Fractography revealed that a majority of the failures were the result of cracks nucleating at, or near, large $\beta-\mathrm{Al}_{3} \mathrm{Mg}_{2}$ precipitates. An example of a crack nucleation region is shown in Fig. 14, where the crack origin (circled area) is clearly associated with a group of $\beta-\mathrm{Al}_{3} \mathrm{Mg}_{2}$ precipitates (arrow). The fatigue data scatter is minimal for the asrolled alloy. This indicates that attempting to improve the microstructure and grain-shape for easier mechanical processing of this material results in an alloy with localized flaws, which could enhance the nucleation of cracks; that is, at the surfaces of hard precipitates in a soft matrix, on voids present along grain boundaries, or along grain boundaries as a result of interconnecting grain boundary precipitates. 


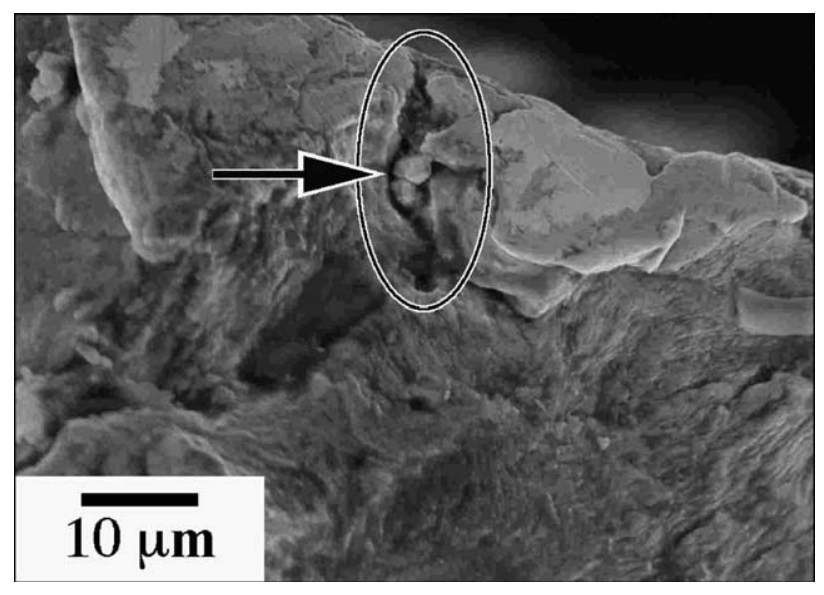

Fig. 14. Backscattered electron SEM micrograph of the fracture surface of a fatigue tested modified 5754 alloy, which was annealed at $600{ }^{\circ} \mathrm{C}$ for $45 \mathrm{~min}$ and aged at $300{ }^{\circ} \mathrm{C} 72 \mathrm{~h}$ and tested at a strain amplitude of $4 \times 10^{-3}$ after 6669 cycles. Circular region indicates the area of crack origin and the arrow denotes a $\beta-\mathrm{Al}_{3} \mathrm{Mg}_{2}$ precipitate, where crack was most likely nucleated.

On a microstructural basis, the high-cycle regime is most dependent on the strength of the matrix. In the low-cycle regime, however, the material response is dependent on the ability of the material to withstand plastic deformation. In the unmodified 5754 alloy, the matrix strength is dictated mainly by the $\mathrm{Mg}$ concentration and the grain and perhaps subgrain boundaries being pinned by the relatively coarse precipitates (at least $1 \mu \mathrm{m}$ diameter).

Alternatively, in the modified alloys, $\mathrm{Al}_{3} \mathrm{Sc}_{1-x} \mathrm{Zr}_{x}$ precipitates further affect strength directly by interacting with dislocations, and indirectly, by affecting grain and subgrain size, thus explaining the strong effect of heattreatment upon fatigue behavior. The relative effect of grain boundaries and fine precipitates is illustrated by comparing the annealed specimens to the more fatigue resistant, annealed and aged specimens. The latter samples contain fine coherent $\mathrm{Al}_{3} \mathrm{Sc}_{1-x} \mathrm{Zr}_{x}$ precipitates and have nearly a 2.6-fold larger grain size than the annealed samples, which have no fine precipitates. Therefore, the positive effect of coherent $\mathrm{Al}_{3} \mathrm{Sc}_{1-x} \mathrm{Zr}_{x}$ precipitates in inhibiting fatigue more than compensates the negative effect due to the increase in grain size, which is known to decrease fatigue resistance. Overall, fine $\mathrm{Al}_{3} \mathrm{Sc}_{1-x} \mathrm{Zr}_{x}$ precipitates contribute more to fatigue resistance than does grain size. Subgrains, however, contribute more to fatigue resistance than the presence of fine $\mathrm{Al}_{3} \mathrm{Sc}_{1-x} \mathrm{Zr}_{x}$ precipitates. Therefore, the addition of Sc and $\mathrm{Zr}$ have both indirect and direct effects on the optimal fatigue strength of the as-rolled alloy.

Cyclic hardening occurred in all of the alloys tested, regardless of heat-treatment. The initial stress response of each alloy is, however, proportional to the extent of strengthening in the alloys. The high precipitate number density and small subgrain diameters observed in the as-

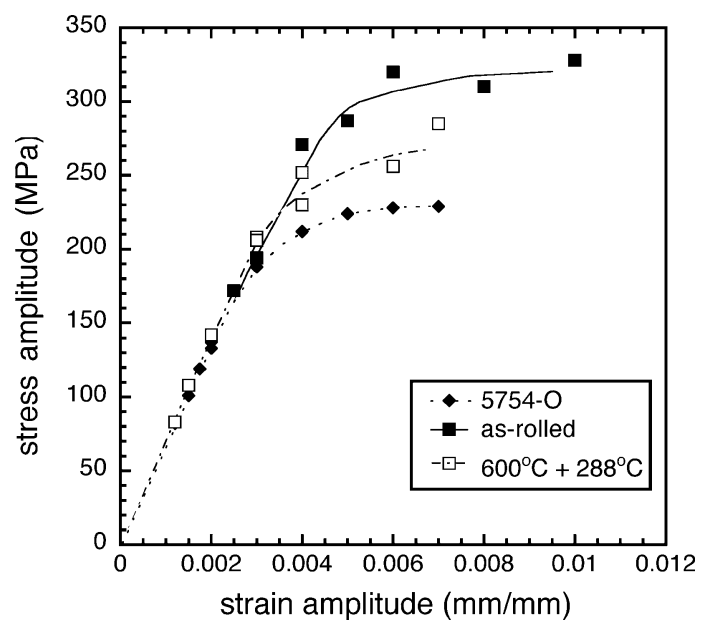

Fig. 15. A plot of stress amplitude versus strain amplitude for modified 5754 and unmodified 5754-O alloys with indicated heat treatments.

rolled alloy resulted in a small amount of cyclic hardening, while the nearly obstacle-free structure of the annealed alloy exhibited a larger amount of cyclic hardening. The existence of cyclic hardening can be attributed to the work-hardening effects of obstacles, whereby dislocations are pinned and segments of mobile dislocations subsequently form dislocation pile-ups [16]. Cyclic hardening continues until the dislocation behavior is stabilized, at which time the alloys exhibit a constant stress response level until crack nucleation occurs. Exceptions to this behavior are exhibited by $\mathrm{Al}-$ $\mathrm{Li}-\mathrm{Cu}$ alloys [17], which soften cyclically after prolonged fatigue as a result of shearing of the ordered $\mathrm{Al}_{3} \mathrm{Li}\left(\mathrm{Ll}_{2}\right.$ structure) precipitates to such an extent that they no longer contribute to the inhibition of dislocation motion. Such softening is not observed in the modified 5754 alloy studied here, indicating that the ordered $\mathrm{Al}_{3} \mathrm{Sc}_{1-x} \mathrm{Zr}_{x}$ precipitates (with the same $\mathrm{Ll}_{2}$ structure as $\mathrm{Al}_{3} \mathrm{Li}$ ) are not sheared, thus maintaining a stable cyclic behavior throughout the fatigue life of the alloy. The cyclic stress-strain responses of modified 5754 specimens with two different heat treatments (as-rolled and $600{ }^{\circ} \mathrm{C}$ for $45 \mathrm{~min}$ plus $288{ }^{\circ} \mathrm{C}$ for $72 \mathrm{~h}$ ) are compared with that of the control 5754-O alloy in Fig. 15 , in which the stress amplitude is determined from the cyclic hysteresis loop recorded near the fatigue half-life of the specimen. These curves demonstrate that the asrolled alloy has the highest degree of hardening, while the 5754-O alloy has the lowest.

\section{Conclusions}

In this work, the evolution of microstructure and mechanical properties was studied as a function of heat treatment in a Sc and Zr modified 5754 aluminum alloy, 
with a composition of $\mathrm{Al}-3.42 \mathrm{Mg}-0.63 \mathrm{Mn}-0.23 \mathrm{Sc}-$ $0.22 \mathrm{Zr}$ (in wt. $\%$ ).

Two populations of $\mathrm{Al}_{3} \mathrm{Sc}_{1-x} \mathrm{Zr}_{x}$ precipitates were present: (i) large incoherent precipitates (in the form of rods and spheroids in the as-rolled plus aged alloy and rods in the as-rolled alloy; the rods break into spheroids in the annealed and annealed plus aged alloys); and (ii) fine coherent $\mathrm{Al}_{3} \mathrm{Sc}_{1-x} \mathrm{Zr}_{x}$ precipitates (observed in all but the annealed alloy). Subgrain boundaries were present in the as-rolled and as-rolled plus aged alloys, but were eliminated upon annealing when recrystallization and perhaps grain growth occurred. A side effect of the aging process is the production of two types of grainboundary precipitates, $\mathrm{Al}_{6} \mathrm{Mn}$ and $\beta-\mathrm{Al}_{3} \mathrm{Mg}_{2}$, which resulted in reduced fatigue resistance.

The tensile strength of the alloys was found to correlate with the evolution of the microstructure. The highest measured tensile strength was for the as-rolled alloy, while the lowest strength was for the annealed alloy, which was stronger than the Sc- and Zr-free 5754O alloy.

Fatigue resistance is the highest for the as-rolled alloy (with the highest static strength) due to the presence of fine $\mathrm{Al}_{3} \mathrm{Sc}_{1-x} \mathrm{Zr}_{x}$ precipitates and a high density of subgrains. On the other hand, the lowest fatigue resistance is observed for the annealed alloy (with the lowest static strength), which has neither subgrains nor fine $\mathrm{Al}_{3} \mathrm{Sc}_{1-x} \mathrm{Zr}_{x}$ precipitates. Therefore, the order of importance for microstructural elements to inhibit fatigue is subgrain boundaries, precipitates, and grain boundaries.

\section{Acknowledgements}

The authors would like to thank A. Sherman, W. Donlon, F. Alberts and J. Bonnen for their support and experimental assistance at Ford Motor Company, Scientific Research Laboratory. Funding from the US Department of Energy, Basic Energy Sciences (grant no. DE-FG02-98ER45721 to Northwestern University) is also gratefully acknowledged.

\section{References}

[1] J.R. Davis, ASM Handbook, vol. 2, ASM, Metals Park, OH, 1990, p. 29

[2] J.S. Vetrano, S.M. Bruemmer, L.M. Pawlowski, I.M. Robertson, Mater. Sci. Eng. A238 (1997) 101-107.

[3] N. Blake, M.A. Hopkins, J. Mater. Sci. 20 (1985) 2861-2867.

[4] R.W. Hyland, Metall. Trans. A 23 (1992) 1947-1955.

[5] L.I. Kaigordova, E.I. Sel'nikhina, E.A. Tkachenko, O.G. Senatorova, Phys. Met. Metall. 81 (5) (1996) 513-519.

[6] Y. Harada, D.C. Dunand, Mater. Sci. Eng. A (2002) in press.

[7] V.I. Elagin, V.V. Zakharov, S.G. Pavlenko, T.D. Rostova, Phys. Met. Metall. 60 (1) (1985) 88-92.

[8] J.S. Vetrano, C.H. Henager, Jr, S.M. Bruemmer, in: A.K. Ghosh, T.R. Bieler (Eds.), Superplasticity and Superplastic Forming 1998, TMS, Metals Park, PA, 1998, pp. 89-98.

[9] Z. Yin, Q. Pan, Y. Zhang, F. Jiaang, Mater. Sci. Eng. A280 (2000) $151-155$.

[10] T. Wirtz, G. Lutjering, A. Gysler, B. Lenczowski, R. Rauh, Mater. Sci. Forum 331-337 (2000) 1489-1494.

[12] N. Ryum, Acta Metall. 17 (1969) 269-278.

[11] D.A. Porter, K.E. Easterling, Phase Transformations in Metals and Alloys, 2nd ed., Chapman and Hall, London, 1992, p. 325.

[13] L.S. Toropova, D.G. Eskin, M.L. Kharakterova, T.V. Dobatkina, Advanced Aluminum Alloys Containing Scandium - Structure and Properties, Gordon and Breach Science Publishers, Moscow, 1998, p. 60.

[14] E.A. Marquis, D.N. Seidman, Acta Mater. 49 (11) (2001) 19091919.

[15] N.E. Dowling, Mechanical Behavior of Materials, 2nd ed., Prentice Hall, Upper Saddle River, NJ, 1999, p. 649.

[16] R. Kral, Phys. Stat. Sol. A 157 (2) (1996) 255-263.

[17] T.S. Srivatsan, E.J. Coyne, Jr, Int. J. Fatigue 8 (7) (1986) $201-$ 208. 